\title{
Evaluation of a hydrothermal process for pretreatment of wheat straw - effect of particle size and process conditions
}

\author{
Héctor A. Ruiz, ${ }^{a}$ Denise S. Ruzene, ${ }^{b}$ Daniel P. Silva, ${ }^{b}$ Mafalda A.C. Quintas, ${ }^{a}$ \\ António A. Vicente ${ }^{\mathrm{a}}$ and José A. Teixeira ${ }^{\mathrm{a} *}$
}

\begin{abstract}
BACKGROUND: Hydrothermal processes are an eco-friendly processes that provide an interesting alternative for chemical utilization of lignocellulosic materials, in which water and crop residues are the only reagents. In this work the effect of process conditions (size distribution of the wheat straw, temperature and time) was evaluated against production of fermentable products.

RESULTS: The use of milled wheat straw fractions as a raw material containing blends of different particle size distribution showed that the latter had an influence on the final sugars in the hydrolysate. Improved values of glucose $(21.1 \%)$ and xylose yields $(49.32 \%)$ present in the hydrolysate were obtained with treatment severity factors of 2.77 and 3.36 , respectively. Mathematical models were developed aimed at establishing the effect of process conditions on monosaccharide concentration and its degradation in the liquor.

CONCLUSION: This work shows that the use of wheat straw blends with various particle sizes has a significant effect on the extraction of fermentable products. The effect of treatment severity, which takes into account both processing time and temperature was also evaluated. These results are of importance for process design.
\end{abstract}

(c) 2010 Society of Chemical Industry

Keywords: hydrothermal process; particle size; lignocellulosic materials; pretreatment; wheat straw

\section{INTRODUCTION}

Lignocellulosic materials are vegetal biomass, mainly made up of cellulose, hemicelluloses and lignin. Such materials are renewable, costless and could be used as a source to produce fuel ethanol. ${ }^{1}$ In recent years, there has been an intensive use of lignocellulosic materials such as hardwoods (Eucalyptus globulus, white birch, hybrid poplar), softwoods (Pinus banksian, fir, red fir) and agricultural residues (corn cobs, wheat straw, rice straw, corn

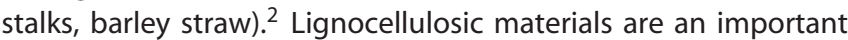
contributor to the world's economy. Agriculture and forest product industries provide a wide range of necessary products used as shelter, packaging, clothing, and fuels, so that lignocellulosic materials can have different uses. For example, sugar cane bagasse is used as fuel and animal feed, and wheat straw can be used either in construction or in the paper industry. Other forms of biomass are deliberately modified from one energy form into another, for example, wood to charcoal, dung to biogas and fertilizer, and sugar to ethanol. Thus, it may be important to measure processed biomass and the separation of its main components (cellulose, hemicellulose and lignin) as they are an actual and potential energy source. ${ }^{3,4}$ This concept is called biorefinery, i.e. co-production of transportation biofuels, bioenergy and marketable chemicals from renewable biomass. ${ }^{5}$

Wheat straw, as an agricultural residue, is one of the most abundant biomass sources in the world. ${ }^{6}$ The straw yield depends on the specific wheat varieties harvested and climatic factors; an average ratio of $1.3 \mathrm{~kg}$ straw $\mathrm{kg}^{-1}$ grain is found for the most common varieties. ${ }^{7,8}$

The purpose of the pretreatment of lignocellulosic material to fermentable products is to remove lignin and hemicellulose, disrupt the crystalline structure of cellulose, and increase the porosity of the materials, so that enzymes can easily access and hydrolyse cellulose. Pretreatment of raw material is perhaps the most crucial single step as it has a large impact on all the other steps in the process, e.g. enzymatic hydrolysis (in terms of digestibility of the cellulose), fermentation (toxicity) and downstream processing (including energy demand). The pretreatment must meet the following requirements: (1) improve the formation of sugar; (2) avoid degradation or loss of carbohydrates; (3) avoid the formation of inhibitory by-products; and (4) have low capital and operational costs. ${ }^{9-11}$

\footnotetext{
Correspondence to: José A. Teixeira, Institute for Biotechnology and Bioengineering, Centre of Biological Engineering, University of Minho, Campus de Gualtar, 4710-057 Braga, Portugal.E-mail:jateixeira@deb.uminho.pt

a IBB-Institute for Biotechnology and Bioengineering, Centre of Biological Engineering, University of Minho, Campus de Gualtar, 4710-057 Braga, Portugal

b ITP-Instituto de Tecnologia e Pesquisa, Tiradentes University, Campus Farolândia, 49032-490 Aracaju/SE, Brazil
} 
Among the existing hydrolysis techniques, the hydrothermal process (autohydrolysis) consists of heating lignocellulosic materials with water at high temperatures $\left(150-230^{\circ} \mathrm{C}\right)$, undergoing hydrolysis reactions in the presence of the hydronium ions generated by water autoionization, which act as a catalyst. ${ }^{12,13}$ Because the bonds of hemicelluloses are the most susceptible, autohydrolysis has been considered a cost-effective method for pretreating lignocellulosic materials. In fact, no chemicals other than water are necessary and hemicelluloses can be converted into hemicellulosic material sugar at good yields with low by-products generation.

Compared specifically with acid hydrolysis, autohydrolysis induces low by-product generation, high pentosan recovery, limited equipment corrosion problems, and reduced operational costs since further neutralization can be omitted. For that reason, the hydrothermal process can be considered an ecofriendly fractionation technology, leading to the separation of hemicelluloses from the remaining structural components of the feedstock. ${ }^{14-19}$

The most important variables in hydrothermal processes are residence time, temperature, particle size and moisture content. Normally, when larger chips are used, heat transfer problems lead to overcooking of the exterior (with associated formation of inhibitors) and incomplete autohydrolysis of the interior. ${ }^{20-22}$ This problem can be overcome by reducing particle size before the application of the pretreatment. This size reduction process not only changes the particle size and shape, but also increases bulk density, improves flow properties, increases porosity, and increases surface area. This higher surface area increases the number of contact points for chemical reaction. ${ }^{23,24}$ Most of the literature deals with raw materials featuring a unimodal particle size distribution, thus leaving behind all the other fractions resulting from milling.

However, from an operational point of view, raw materials are one of the most expensive items in the process; therefore strategies to use all the disposable materials obtained after milling are needed. During the pretreatment, and depending on the operational conditions of the hydrothermal process, polysaccharides (mainly hemicelluloses) are depolymerized to oligomers and monomers, and the corresponding sugar (pentoses and hexoses) can be dehydrated to furfural and hydroxymethylfurfural (HMF). ${ }^{25}$ Such degradation products will impair further fermentation and thus, ethanol production. Hence, thermal degradation of monomers must be minimized during pretreatment.

This work aims at evaluating the effect of particle size distribution of milled wheat straw and hydrothermal pretreatment conditions on the fermentable products obtained from it. To achieve this goal, a $3^{3}$ factorial design considering different wheat straw blends, processing time and temperature was applied. The resulting monomeric sugars in the liquor obtained were analyzed.

\section{EXPERIMENTAL}

\section{Raw material}

Wheat straw was supplied by a local farmer (Elvas, Portugal). The straw was cut into small chips $(1-5 \mathrm{~mm})$ and milled using a laboratory knife mill (Cutting Mill SM 2000, Retsch, Germany). Aliquots of the homogenized wheat straw lot were subjected to moisture determination (drying at $105^{\circ} \mathrm{C}$ to constant weight). Approximately, $2 \mathrm{~g}$ of ground wheat straw were treated with $10 \mathrm{~mL}$ of $72 \%(\mathrm{w} / \mathrm{w}) \mathrm{H}_{2} \mathrm{SO}_{4}$, stirring for $7 \mathrm{~min}$ at $45^{\circ} \mathrm{C}$. The reaction was interrupted by adding $50 \mathrm{~mL}$ of distilled water and the mixture was then transferred to a $500 \mathrm{~mL}$ Erlenmeyer flask

\begin{tabular}{|c|c|c|c|}
\hline \multicolumn{4}{|c|}{ Wheat straw size distribution (frequency) } \\
\hline Particle size (mm) & B1 & B2 & B3 \\
\hline 1 & 0.25 & 0.1 & 0.1 \\
\hline 0.5 & 0.25 & 0.1 & 0.4 \\
\hline 0.3 & 0.25 & 0.4 & 0.4 \\
\hline 0.15 & 0.25 & 0.4 & 0.1 \\
\hline Mean size (mm) & 0.488 & 0.330 & 0.435 \\
\hline Size variance $\left(\mathrm{mm}^{2}\right)$ & 0.103 & 0.061 & 0.049 \\
\hline
\end{tabular}

and the volume adjusted to $275 \mathrm{~mL}$. The flask was autoclaved for $30 \mathrm{~min}$ at $121^{\circ} \mathrm{C}$ for complete hydrolysis of oligomers. The mixture was filtered and the hydrolysate adjusted to $500 \mathrm{~mL}$. The hydrolysate was analyzed by high performance liquid chromatography (HPLC) with a MetaCarb $87 \mathrm{H}(300 \times 7.8 \mathrm{~mm}$, Varian, USA) column at $45^{\circ} \mathrm{C}$ using a Jasco chromatograph with refraction-index detector (Jasco, Tokyo, Japan); the mobile phase was $0.005 \mathrm{~mol} \mathrm{~L}^{-1} \mathrm{H}_{2} \mathrm{SO}_{4}$ at a flow rate of $0.6 \mathrm{~mL} \mathrm{~min}^{-1}$. The samples were analyzed for glucan, xylan, arabinan and acetyl groups. Sugar concentrations reported as xylan and glucan, were determined using calibration curves of pure compounds. The solid obtained in the filtration after hydrolysis was oven-dried and weighed. The mass obtained corresponded to the residual lignin (Klason lignin) and the soluble lignin was determined by spectroscopy at $280 \mathrm{~nm}$.,26

The milled material, under conditions usually applied in hydrolysis experiments $(0.9 \mathrm{~mm})$, and its residues were initially separated into fractions $>1.0 \mathrm{~mm}$ (mesh 18), $1.0-0.5 \mathrm{~mm}$ (mesh 35), $0.5-0.3 \mathrm{~mm}$ (mesh 50) and $<0.3 \mathrm{~mm}$ (basis) using a portable sieve shaker (Model Analysette, Fritsch, Germany). These fractions were mixed in different proportions to achieve mixtures with different mean particle sizes and variances (Table 1).

\section{Hydrothermal process}

Hydrothermal processing was performed in $160 \mathrm{ml}$ total volume stainless steel cylinder reactors and then submerged in a Julabo oil bath with open heating circulator (Julabo Labortechnik GmbH, Seelbach, Germany) with PID temperature control under different operating conditions. Blends with different size distributions (Table 1) were processed under different thermal treatments.

Temperature and residence time were chosen based on values normally used for hydrolysis of other lignocellulosic materials. For this, water was added to samples of wheat straw blends in a solid: liquid ratio of $1: 10(\mathrm{~g}: \mathrm{mL})$ in a closed and pressurized vessel. The moisture content of wheat straw was considered to be water in the material balances.

The reactor was heated following the different operating conditions established by the factorial design (see Statistical Procedures section). At the end of the desired reaction time, the reactor was removed from the oil bath and immediately immersed in an ice bath to quench the reaction. The solid and liquid were separated via vacuum filtration. The effects of time and temperature on wheat straw were interpreted based on the severity parameter $\log R_{0} \cdot{ }^{27}$ Two true replicates of each experiment were carried out. 
Table 2. Composition of wheat straw (\% dry weight)

\section{Components}

Composition (\%)

$$
\begin{aligned}
& \text { Cellulose* } \\
& \text { Hemicellulose }
\end{aligned}
$$

Xylan

Arabinan

Acetyl group

Total lignin

Soluble lignin

Klason lignin

Ash

* Measured as glucan.

\section{Chemical characterization of liquors from hydrothermal process}

Hydrolysate samples were analyzed by HPLC using a Jasco chromatograph 880-PU intelligent pump (Jasco, Tokyo, Japan). Glucose, xylose, arabinose and acetic acid concentrations were determined with a refractive index (RI) detector and a MetaCarb $87 \mathrm{H}(300 \times 7.8 \mathrm{~mm})$ column at $60{ }^{\circ} \mathrm{C}$, using $0.005 \mathrm{~mol} . \mathrm{L}^{-1} \mathrm{H}_{2} \mathrm{SO}_{4}$ as eluent at $0.7 \mathrm{~mL} \cdot \mathrm{min}^{-1}$ flow rate. Furfural and hydroxymethylfurfural were determined using a Jasco chromatograph 2080-PU intelligent pump (Jasco) equipped with a Jasco 2070-UV intelligent UV-VIS detector (Jasco) at $276 \mathrm{~nm}$ and a Jasco AS-2057 Plus intelligent auto sampler (JasCo) with a CC 250/4 6 Nucleosil 120-5 $C_{18}$ column (Macherey-Nagel, Düren, Germany) at room temperature, using acetonitrile-water in a ratio $1: 8(\mathrm{v} / \mathrm{v})$ containing $10 \mathrm{~g} \mathrm{~L}^{-1}$ acetic acid as the eluent, at a flow rate of $0.9 \mathrm{~mL} \mathrm{~min}^{-1}$. All samples were filtered through $0.45 \mu \mathrm{m}$ membranes before analysis. ${ }^{28}$

\section{Statistical procedures}

Experiments were conducted following a $3^{3}$ design ${ }^{29}$ at three residence times (10,30 and $60 \mathrm{~min})$, three processing temperatures $\left(160,180\right.$ and $\left.200^{\circ} \mathrm{C}\right)$ using three blends with different particle size distributions (see size distribution characterization in Table 1). The experimental design can be seen in Table 3, together with results. Results were analysed using the Experimental Design package of STATISTICA ${ }^{\text {TM }}$ v 6.0 (Statsoft ${ }^{\circledR}$, Tulsa, OK, USA). Models were proposed based on ANOVA for selecting significant variables and interactions $(<0.05)$. The coefficient of determination $\left(R^{2}\right)$, residuals histogram and the $95 \%$ Standard Error of the parameters (SE) were obtained directly from the software and used as statistical indicators for the models.

\section{RESULTS AND DISCUSSION}

\section{Raw material composition}

Wheat straw composition varies depending on plant variety and culture conditions. The chemical composition of the wheat straw samples tested in this work is presented in Table 2. Wheat straw moisture content was $8 \%$ of dry weight. The highest lignocellulosic materials present in higher amounts were cellulose with $37.4 \%$ (estimated as glucan content) followed by hemicellulose with $33.8 \%$ and lignin representing $26.8 \%$ of dry weight. Hemicellulose fraction was composed mainly of xylose (29.4\%), arabinose $(1.9 \%)$ and acetyl groups (2.5\%). This chemical composition is in good agreement with other values found in the literature for this feedstock material. ${ }^{30-32}$

\section{Effect of the hydrothermal process on liquor composition}

The different blends of wheat straw (Table 1) were subjected to different conditions of pretreatment and sugars obtained for each hydrolysate are presented in Table 3. It can be observed that the formation of these compounds varied for each set of hydrolysis conditions employed and for the different wheat straw blends tested. The highest glucose yield found was $21.1 \%$ corresponding to a severity factor $R_{0}=2.77\left(160^{\circ} \mathrm{C}, 10 \mathrm{~min}\right)$, for B3 blend. For xylose, the highest yield was $49.32 \%$ corresponding to a hydrolysis treatment with a severity factor $R_{0}$ of $3.36\left(180^{\circ} \mathrm{C}, 10 \mathrm{~min}\right)$ for blend B2. For arabinose the highest yield observed was $14.48 \%$ corresponding to a severity factor $R_{0}=3.94\left(200^{\circ} \mathrm{C}, 10 \mathrm{~min}\right)$ for B1.

The effect of hydrothermal treatment can be evaluated by the total sugar present in the liquor obtained and the solid yield of each treatment (Fig. 1(A) and 1(B), respectively).

Regarding total sugar present in the liquor, results show that severity treatments higher than 4.13 led to increased sugar extraction (0.04-0.26 $\left.\mathrm{mol} \mathrm{L}^{-1}\right)$. In contrast, lower severities led to poor release of sugars. Similar behavior has been reported by Liavoga et al. ${ }^{33}$, where highest sugar production was obtained with higher severity treatments.

As for solid residue yield, Fig. 1(B) shows that for the less severe conditions $\left(R_{0}<3.94\right)$, the solid solubilization that occurred was very low. For higher severity treatments, a lower solid yield was obtained-e.g. around 55\% of original material was solubilized as a consequence of pretreatment from the severity factor of log $R_{0}=4.72$. This decrease could be correlated with the solubilization of sugars, principally hemicellulose. These results are in good agreement with previous reports. ${ }^{15,34}$

To better evaluate the effect of treatment severity and type of straw blend, molar percentages of xylose, arabinose and glucose in the liquors were also estimated. Moreover, the molar percentages of the thermal degradation products of these sugars (acetic acid, hydroxymethylfurfural (HMF), and furfural) were quantified (Fig. 2).

From these results, it can be observed that different severity factors lead to different compositions of the liquor. In terms of sugars composition, it can be seen that xylose and glucose are degraded for higher severity treatments (Fig. 2(A) and (B)), whereas arabinose seems to be more resistant to heat degradation (Fig. 2(C)). Regarding the degradation products, the intensity of the heat treatment plays a more important role in HMF and furfural production (Fig. 2(E) and (F)) than in the formation of weak acids (here assessed in terms of acetic acid (\%), Fig. 2(D)). The formation of HMF was enhanced at higher process severity ( $\log R_{0}=4.72$ ) and was consistent with the decomposition of glucose. Furfural production was a maximum at $200^{\circ} \mathrm{C}$ for $60 \mathrm{~min}$. High temperaturea and/or prolonged heating resulted in a loss of xylose or arabinose, probably because it was converted to furfural or it reacted with peptide amino groups to give Maillard browning products that resulted in a dark color and a burntsugar odor. ${ }^{33} \mathrm{~A}$ similar effect of temperature on HMF and furfural formation has been reported. ${ }^{15}$ The production of acetic acid was steady and not affected by treatment severity; this can be partially explained by the lower content of acetyl groups in the wheat straw.

For every tested treatment condition it can also be observed that the main sugar fraction in the liquor is xylose, and lower quantities of glucose are observed; this is because the glucan remained in the solid phase and only a small part of it was depolymerized to glucose. ${ }^{15}$ 


\begin{tabular}{|c|c|c|c|c|c|c|}
\hline \multirow[b]{2}{*}{ Temperature $\left({ }^{\circ} \mathrm{C}\right)$} & \multirow[b]{2}{*}{ Time (min) } & \multirow[b]{2}{*}{$\log \left(R_{0}\right)$} & \multirow[b]{2}{*}{ Blend } & \multicolumn{3}{|c|}{ Molar percentages } \\
\hline & & & & Glucose & Xylose & Arabinose \\
\hline \multirow[t]{9}{*}{160} & 10 & 2.77 & B1 & $19.07 \pm 0.57$ & $47.36 \pm 0.90$ & $8.5 \pm 0.66$ \\
\hline & & & B2 & $17.27 \pm 0.59$ & $46.24 \pm 0.90$ & $6.47 \pm 0.02$ \\
\hline & & & B3 & $21.10 \pm 0.46$ & $48.02 \pm 0.55$ & $6.88 \pm 0.80$ \\
\hline & 30 & 3.24 & B1 & $16.66 \pm 0.39$ & $41.25 \pm 0.44$ & $4.96 \pm 0.11$ \\
\hline & & & B2 & $17.76 \pm 0.25$ & $41.61 \pm 1.96$ & $6.14 \pm 1.15$ \\
\hline & & & B3 & $16.06 \pm 0.19$ & $39.43 \pm 0.59$ & $5.83 \pm 0.73$ \\
\hline & 60 & 3.54 & B1 & $11.90 \pm 1.01$ & $36.12 \pm 5.5$ & $7.21 \pm 4.19$ \\
\hline & & & B2 & $11.32 \pm 0.28$ & $24.71 \pm 1.45$ & $11.71 \pm 0.60$ \\
\hline & & & B3 & $11.17 \pm 0.25$ & $24.11 \pm 0.79$ & $10.16 \pm 0.10$ \\
\hline \multirow[t]{9}{*}{180} & 10 & 3.36 & B1 & $20.65 \pm 0.66$ & $46.57 \pm 2.61$ & $7.99 \pm 0.94$ \\
\hline & & & B2 & $20.40 \pm 0.66$ & $49.32 \pm 1.58$ & $7.20 \pm 2.46$ \\
\hline & & & B3 & $18.5 \pm 0.28$ & $43.47 \pm 2.11$ & $7.23 \pm 0.27$ \\
\hline & 30 & 3.83 & B1 & $12.5 \pm 1.16$ & $32.15 \pm 3.56$ & $8.25 \pm 0.34$ \\
\hline & & & B2 & $9.33 \pm 0.21$ & $24.94 \pm 0.40$ & $14.45 \pm 1.03$ \\
\hline & & & B3 & $11.27 \pm 1.63$ & $30.65 \pm 3.51$ & $10.09 \pm 0.21$ \\
\hline & 60 & 4.13 & B1 & $3.56 \pm 0.34$ & $12.87 \pm 0.49$ & $11.53 \pm 0.43$ \\
\hline & & & B2 & $3.78 \pm 0.47$ & $13.02 \pm 0.40$ & $13.65 \pm 1.5$ \\
\hline & & & B3 & $4.99 \pm 0.40$ & $15.23 \pm 1.17$ & $13.4 \pm 2.58$ \\
\hline \multirow[t]{9}{*}{200} & 10 & 3.94 & B1 & $12.96 \pm 0.13$ & $6.87 \pm 0.21$ & $14.48 \pm 0.04$ \\
\hline & & & B2 & $8.61 \pm 1.09$ & $25.49 \pm 0.56$ & $3.13 \pm 0.21$ \\
\hline & & & B3 & $17.88 \pm 2.32$ & $38.84 \pm 1.81$ & $5.8 \pm 0.28$ \\
\hline & 30 & 4.42 & B1 & $2.6 \pm 0.0 .3$ & $2.25 \pm 0.08$ & $3.42 \pm 0.05$ \\
\hline & & & B2 & $3.43 \pm 0.22$ & $17.04 \pm 0.35$ & $13.19 \pm 0.06$ \\
\hline & & & B3 & $3.62 \pm 0.85$ & $15.92 \pm 0.24$ & $9.77 \pm 0.97$ \\
\hline & 60 & 4.72 & B1 & $0.61 \pm 0.00$ & $1.45 \pm 0.07$ & $0.93 \pm 0.05$ \\
\hline & & & B2 & $0.84 \pm 0.17$ & $10.06 \pm 0.29$ & $0.33 \pm 0.00$ \\
\hline & & & B3 & $0.62 \pm 0.07$ & $10.30 \pm 0.19$ & $0.28 \pm 0.00$ \\
\hline
\end{tabular}
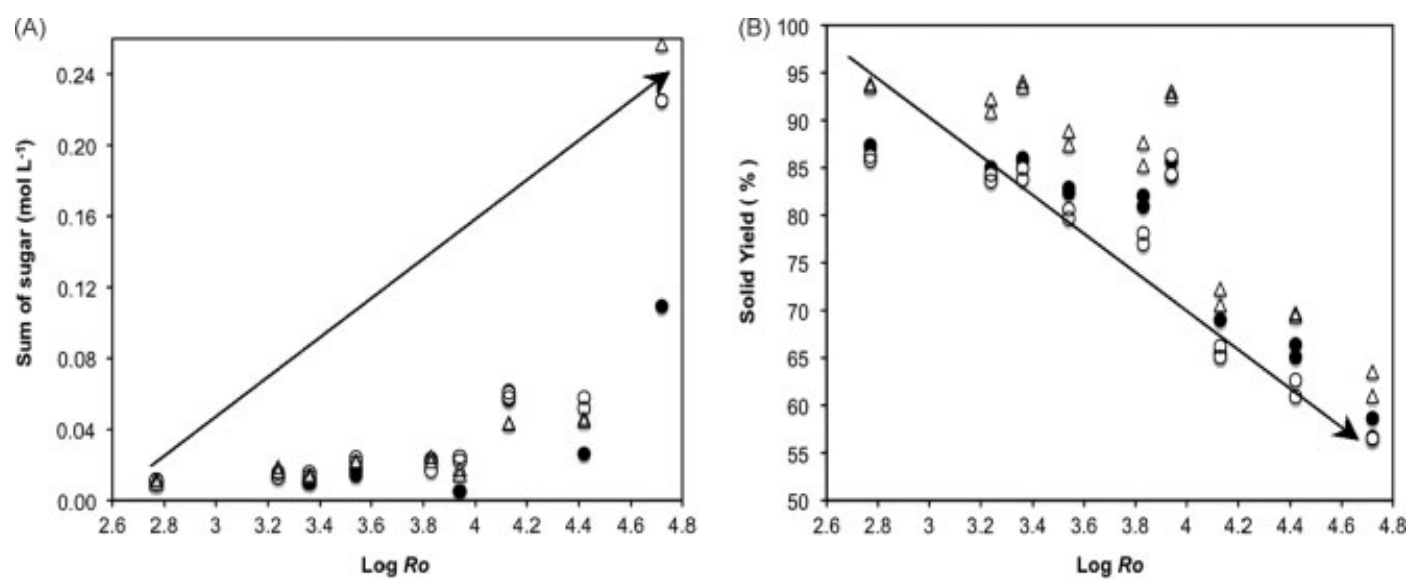

Figure 1. Effect of hydrothermal process on the sum of sugar contents (respective degradation products) and solid yield present in the liquor. (A) Sum of sugar contents; (B) solid yield: B1 $(\bullet)$; B2 $(O)$ and B3 $(\triangle)$. The arrows represent main trends.

When using autohydrolysis, the hydrolysate reported by Carvalheiro et al. ${ }^{15}$ contains $0.255,0.1,0.066,0.584,0.017$, and 0.157 (mol \%) for xylose, arabinose, glucose, acetic acid, HMF and furfural. The severity factors used in that work varied between 3.96 and 4.68. These results are in agreement with the sugars content obtained in the present work (see Table 3). These results contrast with that obtained for other materials also using hot-compressed water. $^{19}$

\section{Evaluation of process conditions: variance, time and temperature}

Use of the hydrothermal process with wheat straw has two different and competing objectives: maximizing the extraction of sugar monomers (which can be assessed by the release of glucose, xylose and arabinose into the liquor) and minimizing the degradation of these monosaccharides. These response variables were studied under different operating conditions (temperature and time) 

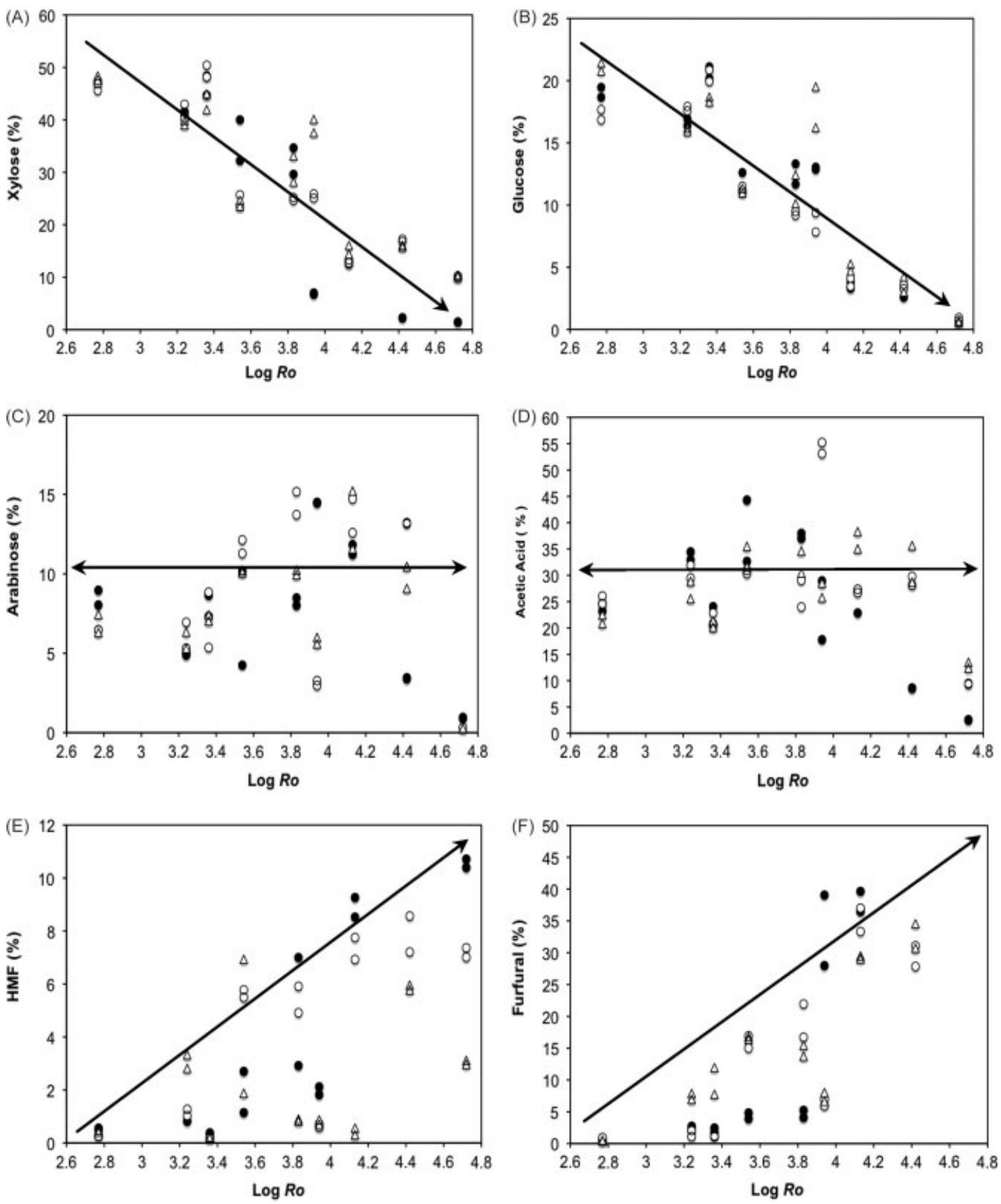

Figure 2. Relationship between severity parameters and molar percentage of hydrolysed sugars and the respective degradation products: (A) xylose; (B) arabinose; (C) glucose; (D) acetic acid, (E) Hydroxymethylfurfural (HMF), and (F) furfural. Wheat straw blends: B1 (•); B2 (O) and B3 $(\triangle)$. The arrows represent main trends.

in wheat straw blends with different particle size distributions (evaluated by the variance of the distribution, Table 1).

The extraction of sugars, evaluated by the sum of glucose, xylose and arabinose molar concentrations in the liquor, was significantly affected by processing time and temperature and by the variance of wheat straw particle size ( $5 \%$ significance level). These effects can be described by the following model:

Sum of sugars $=a+(b \cdot \operatorname{Var})+(c \cdot t)+(d \cdot \operatorname{Var} \cdot T)+(e \cdot \operatorname{Var} \cdot t)+(f \cdot T \cdot t)$

where Var is the variance of size distribution of the blends $\left(\mathrm{mm}^{2}\right)$; $t$ is residence time (min); $T$ is temperature $\left({ }^{\circ} \mathrm{C}\right) ; a, b, c, d$, e and $f$ are estimated parameters.
Table 4 shows the estimated parameters ( $\pm 95 \%$ confidence level error) and regression evaluation on the basis of adjusted $R^{2}$ and the histogram of residuals. The positive value of the estimate for $b$ may indicate that blends with size distribution variance, i.e. higher heterogeneity of particle sizes, favour sugars extraction. Processing time has a negative effect on the sum of sugars $(c<0)$. However, this is probably due to the fact that longer treatments lead to further sugar degradation and is not directly related with hemicellulose extraction. The same hypothesis can be supported for the estimates of time and temperature interactions with the type of blend used ( $d$ and $e$ parameters).

Percentage of glucose and xylose in the liquor are important parameters since higher degradation of these sugars may impair 
Table 4. Estimated parameters and regression evaluation on the basis of adjusted $R^{2}$ and histogram residuals of the hydrothermal process optimization

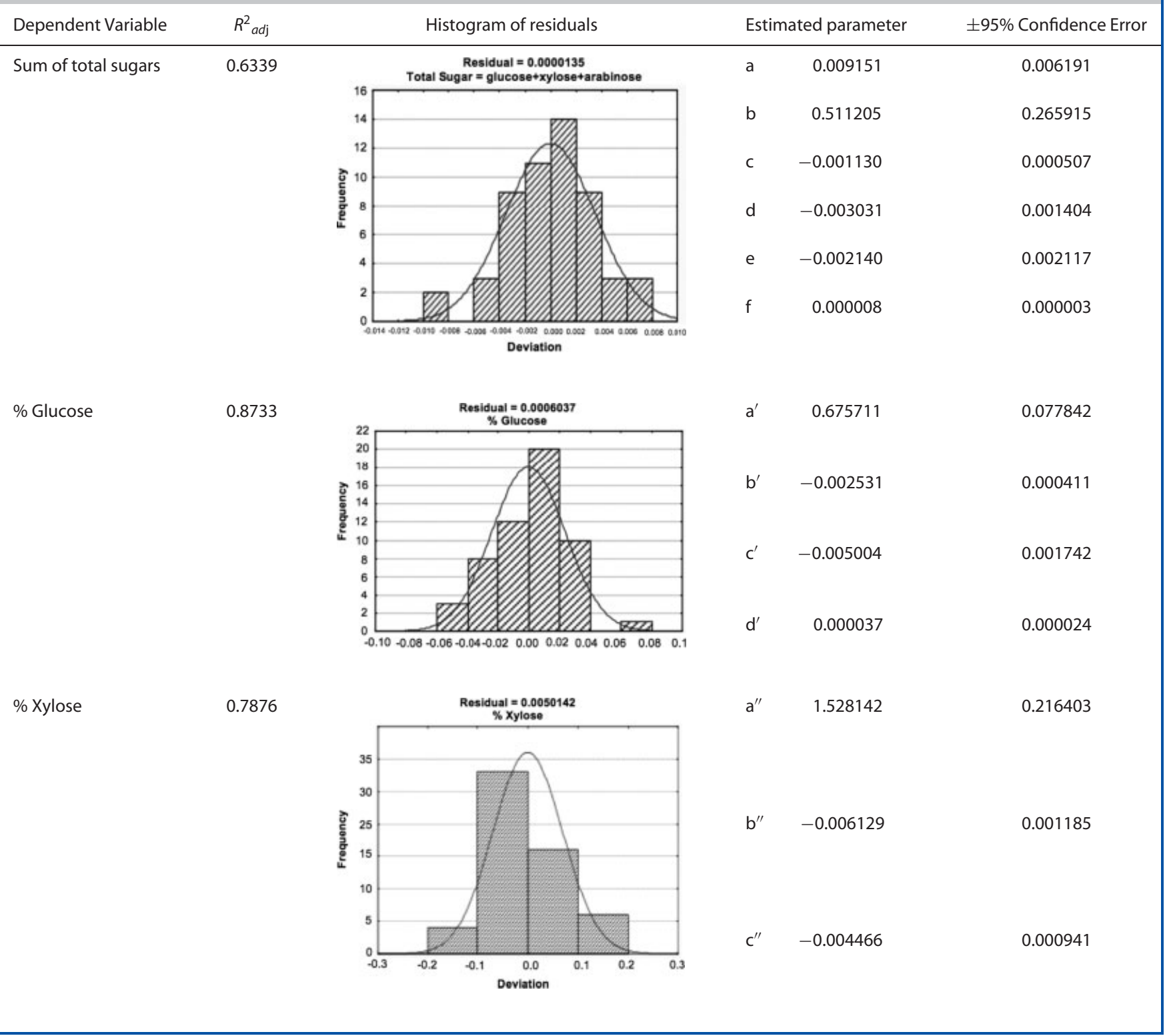

the use of liquor for fermentation purposes. Results show that both percentage glucose and percentage xylose were significantly affected by both temperature and processing time, and not by the particle size distribution.

$$
\begin{aligned}
\% \text { glu cose } & =a^{\prime}+\left(b^{\prime} \cdot T\right)+\left(c^{\prime} \cdot t\right)+\left(d^{\prime} \cdot t^{2}\right) \\
\% \text { xylose } & =a^{\prime \prime}+\left(b^{\prime \prime} \cdot T\right)+\left(c^{\prime \prime} \cdot t\right)
\end{aligned}
$$

where $t$ is residence time ( $\min ) ; T$ is temperature $\left({ }^{\circ} \mathrm{C}\right) ; a^{\prime}, b^{\prime}, c^{\prime}, d^{\prime}$, $a^{\prime \prime}, b^{\prime \prime}$ and $c^{\prime \prime}$ are estimated parameters.

Results show that, the amount of glucose in the liquor was strongly affected by heat treatment, making the type of blend used non-significant. This observation is supported by the negative values of $b^{\prime}$ and $c^{\prime}$ parameter estimates (Table 4). The percentage of xylose was the main component in the liquor obtained for every tested treatment (Table 3). However, processing time and temperature also significantly affected this sugar, while no effect of the type of blend was observed (Table 4).

These results show that although the type of blend has an influence on sugar extraction from the wheat straw, it has no effect on the thermal degradation of these compounds once they are free in the syrup. Also, such results are indicative that thermal degradation occurs when these sugars are in the liquor and not during the extraction process. This makes the use of milled wheat straw blends with high heterogeneity of particle sizes even more interesting, since it may lead to higher sugar extraction, thus compensating the unavoidable sugar degradation due to the heat treatment.

\section{CONCLUSIONS}

In this work, the effect of using milled wheat straw blends of different particle size distributions on sugar monomers extraction and generation of fermentable products was studied. Results 
showed that although variation of the size distribution does not affect sugar degradation in the liquor, it has a selective influence over the extraction of the sum of total sugars (glucose, xylose and arabinose). Thus, it can be established that the use of a blend with defined percentages of the various particle sizes (preferably with a high size variability) is an important parameter to establish before carrying out a pretreatment. These results contribute to improving total monosaccharide recovery for treatments of the same severity.

\section{ACKNOWLEDGEMENTS}

The authors thank the ALBAN programme for PhD fellowship support.

\section{REFERENCES}

1 Ruzene D, Silva D, Vicente A, Gonçalves A and Teixeira J, An alternative application to the Portuguese agro-industrial residue: wheat straw. Appl Biochem Biotechnol. 147:453-464 (2008).

2 Garrote G, Domínguez H and Parajó JC, Hydrothermal processing of lignocellulosic materials. Holz Roh Werkst. 57:191 - 202 (1999).

3 Chum H, Biomass and renewable fuels. Fuel Process Technol 71:187-195 (2001).

4 Callé F, The Biomass Assessment Handbook: Bioenergy for a Sustainable Environment. Earthscan, London, pp. 27-40 (2007).

5 Cherubini F and Ulgiati S, Crop residues as raw materials for biorefinery systems - A LCA case study. Appl Energy 87:47-57 (2010).

6 Ergudenler $A$ and Ghaly $A E$, Determination of reaction kinetics of wheat straw using thermogravimetric analysis. Appl Biochem Biotechnol 34-35:75-91 (1992).

7 Petersen PB, Separation and characterization of botanical components of straw. Agric Progress 63:8-23 (1987).

8 Montane D, Farriol X, Salvado J, Jollez P and Chornet E, Application of steam explosion to the fractionation and rapid vapor-phase alkaline pulping of wheat straw. Biomass Bioenergy 14:261-276 (1998).

9 Kumar P, Barrett DM, Delwiche MJ and Stroeve P, Methods for pretreatment of lignocellulosic biomass for efficient hydrolysis and biofuel production. Ind Eng Chem Res 48:3713-3729 (2009).

10 Sun $Y$ and Cheng J, Hydrolysis of lignocellulosic materials for ethanol production: a review. Bioresource Technol 83:1-11 (2002).

11 ScheperT, Advances in Biochemical Engineering/Biotechnology. Springer, Berlin, pp. 41-65 (2007).

12 Targonsky Z, Autohydrolysis extraction process as a pretreatment of lignocelluloses for their enzymatic hydrolysis. Acta Biotechnol 5:353-361 (1985).

13 Garrote G, Domínguez H and Parajó JC, Kinetic modelling of corncob autohydrolysis. Process Biochem 36:571-578 (2001).

14 Sreenath HK, Koegel RG, Moldes AB, Jeffries TW and Straub RJ, Enzymic saccharification of alfalfa fibre after liquid hot water pretreatment. Process Biochem 35:33-41 (1999).

15 Carvalheiro F, Silva-Fernandes T, Duarte LC and Gírio FM, Wheat straw autohydrolysis: process optimization and products characterization. Appl. Biochem Biotechnol 153:84-93 (2009).
16 Vegas R, Kabel M, Schols HA, Alonso JL and Parajo JC, Hydrothermal processing of rice husks: effects of severity on product distribution. J Chem Technol Biotechnol 83:965-972 (2008).

17 Walsum GPV, Allen SG, Spencer MJ, Laser MS, Antal MJ and Lynd LR, Conversion of lignocellulosics pretreated with liquid hot water to ethanol. Appl Biochem Biotechnol 57-58:157-169 (1996).

18 Pérez JA, González A, Oliva JM, Ballesteros I and Manzanares P, Effect of process variables on liquid hot water pretreatment of wheat straw for bioconversion to fuel-ethanol in a batch reactor. $J \mathrm{Chem}$ Technol Biotechnol 82:929-938 (2007).

19 Yu G, Yano S, Inoue H, Inoue S, Endo T and Sawayama S, Pretreatment of rice straw by a Hot-Compressed water process for enzymatic hydrolysis. Appl Biochem Biotechnol 160:539-551 (2010).

20 Duff S and Murray W, Bioconversion of forest products industry waste cellulosics to fuel ethanol: a review. Bioresource Technol 55:1-33 (1996).

21 Brownell $\mathrm{H}$ and Saddler J, Steam-explosion pretreatment for enzymatic hydrolysis. Biotechnol Bioeng Symp 14:55-68 (1984).

22 Ballesteros I, Oliva JM, Navarro AA, González A, Carrasco J and Ballesteros M, Effect of chip size on steam explosion pretreatment of softwood. Appl Biochem Biotechnol 84-86:97-110 (2000).

23 Drzymala Z, Industrial Briquetting - Fundamentals and Methods. PWNPolish Scientific Publishers, Warszawa, 13 (1993).

24 Schell D and Harwood C, Milling of lignocellulosic biomass. Appl Biochem Biotechnol 45:159-168 (1994).

25 Quintas M, Guimarães C, Baylina J, Brandão TRS and Silva CLM, Multiresponse modelling of the caramelisation reaction. Innov Food Sci Emerg Technol 8:306-315 (2007).

26 Rocha GJ, Deslignificação de bagaço de cana de açúcar assistida por oxigênio. Tese de Doutorado, Universidade Federal de S. Carlos. (2000).

27 Overend R, Chornet E and Gascoigne J, Fractionation of lignocellulosics by steam-aqueous pretreatments. Philos Trans $R$ Soc $A$ 321:523-5361987.

28 Mussatto SI and Roberto IC, Chemical characterization and liberation of pentose sugars from brewer's spent grain. J Chem Technol Biotechnol 81:268-274 (2006).

29 Box G, Hunter J and Hunter W, Statistics for Experimenters. An Introduction to Design, Data Analysis, and Model Building. John Wiley \& Sons, New York (1978).

30 Linde M, Jakobsson E, Galbe M and Zacchi G, Steam pretreatment of dilute H2SO4-impregnated wheat straw and SSF with low yeast and enzyme loadings for bioethanol production. Biomass Bioenergy 32:326-332 (2008).

31 Zimbardi F, Viggiano D, Nanna F, Demichele $M$, Cuna D and Cardinale G, Steam explosion of straw in batch and continuous systems. Appl Biochem Biotechnol 77:117-126 (1999).

32 Bjerre A, Olesen A, Fernqvist T, Plöger A and Schmidt A, Pretreatment of wheat straw using combined wet oxidation and alkaline hydrolysis resulting in convertible cellulose and hemicellulose. Biotechnol Bioeng 49:568-577 (2000).

33 Liavoga $A B$, Bian $Y$ and Seib PA, Release of $d$-xylose from wheat straw by acid and xylanase hydrolysis and purification of xylitol. J Agric Food Chem 55:7758-7766 (2007).

34 Pérez JA, Ballesteros I, Ballesteros M, Sáez F, Negro MJ and Manzanares $\mathrm{P}$, Optimizing liquid hot water pretreatment conditions to enhance sugar recovery from wheat straw for fuel-ethanol production. Fuel 87:3640-3647 (2008). 